\title{
Magnetism in dilute magnetic oxide thin films based on $\mathrm{SnO}_{2}$
}

\author{
C. B. Fitzgerald, M. Venkatesan, L. S. Dorneles, R. Gunning, P. Stamenov, and J. M. D. Coey \\ School of Physics, Trinity College, Dublin 2, Ireland \\ P. A. Stampe and R. J. Kennedy \\ Department of Physics, Florida A\&M University, Tallahassee, Florida 32307, USA
}

\author{
E. C. Moreira \\ Centro Universitario Franciscano, 97010-032, Santa Maria-RS, Brazil
}

\author{
U. S. Sias \\ Instituto de Fisica, Universidade Federal do Rio Grande do Sul, 91501-970, Porto Alegre-RS, Brazil
}

(Received 24 October 2005; revised manuscript received 16 March 2006; published 12 September 2006)

\begin{abstract}
Thin films of $\mathrm{SnO}_{2}$ prepared by pulsed-laser deposition on R-cut sapphire substrates exhibit ferromagnetic properties at room temperature when they are doped with $\mathrm{Cr}, \mathrm{Mn}, \mathrm{Fe}, \mathrm{Co}$, or $\mathrm{Ni}$, but not with other $3 d$ cations. Extrapolated Curie temperatures are generally in excess of $500 \mathrm{~K}$. The moment of the films is roughly independent of doping level, from $0.1-15$ at. \%, with a value per unit substrate area of $200 \pm 100 \mu_{\mathrm{B}} \mathrm{nm}^{-2}$. When magnetization is expressed as a moment per $3 d$ dopant ion, it varies from more than the spin-only value at low concentrations to less than $0.2 \mu_{\mathrm{B}}$ /ion near the percolation threshold. Greatest values are found for iron. The magnetization of the films is highly anisotropic with values when the field is applied perpendicular to the substrate more than double the in-plane values. There is little hysteresis except at high doping levels. The oxides are degenerate $n$-type semiconductors with a Hall mobility of $100 \mathrm{~cm}^{2} \mathrm{~V}^{-1} \mathrm{~s}^{-1}$ and $1.4 \times 10^{19}$ carriers $\mathrm{cm}^{-3}$ in a one-band model, but no anomalous Hall effect or magnetoresistance was observed at room temperature. The data are discussed in relation to (a) the donor impurity-band model of ferromagnetism in semiconductors and (b) the magnetic defect model.
\end{abstract}

DOI: 10.1103/PhysRevB.74.115307

PACS number(s): 75.50.Pp, 73.43.Qt, 74.25.Gz

\section{INTRODUCTION}

Over the past four years, there have been many reports on ferromagnetism above $300 \mathrm{~K}$ in thin films of wide-gap semiconductors doped with a few percent of $3 d$ transition-metal ions. The materials are oxides- $\mathrm{TiO}_{2},{ }^{1,2} \mathrm{ZnO},{ }^{3-7,12} \mathrm{SnO}_{2},{ }^{8-12}$ or nitrides- $\mathrm{GaN},{ }^{13} \mathrm{AlN}{ }^{14}$. The $3 \mathrm{~d}$ dopants are $\mathrm{Sc}, \mathrm{Ti}, \mathrm{V}, \mathrm{Cr}$, $\mathrm{Mn}, \mathrm{Fe}, \mathrm{Co}$, or Ni. There is a recent review of results in $\mathrm{ZnO}$ and $\mathrm{GaN}$ by Liu et al. ${ }^{15}$

High-temperature ferromagnetism was completely unexpected in these hosts because the magnetic doping level $x$, defined as the fraction of cations which are $3 d$ transition metals, lies far below the percolation threshold, $x_{\mathrm{p}}$, needed for long-range order based on superexchange or double exchange interactions. In some cases $x$ can be as low as $1-2 \%{ }^{1,16}$ Furthermore these ferromagnets are usually $n$ type, unlike the well-studied III-V semiconductors such as $\left(\mathrm{Ga}_{1-x} \mathrm{Mn}_{x}\right)$ As, which are $p$ type, and show Curie temperatures of up to $170 \mathrm{~K}$ in thin films with $x=8 \% .{ }^{17}$ Exchange in that case is mediated by holes in the As $4 p$ band which are created by the Mn doping. Moreover, it is known that the $p d$ exchange coefficient $\beta$ is several times greater than the $s d$ exchange coefficient $\alpha,{ }^{18}$ so $n$-type dilute magnetic semiconductors with smaller doping would not have been expected to order magnetically at temperatures above $50 \mathrm{~K}$. Even when a mechanism for long-range exchange coupling exists, the high Curie temperatures are baffling. No ferromagnet has a higher $T_{\mathrm{c}}$ than cobalt $(1390 \mathrm{~K})$. The Curie temperature scales as $x$ or $x^{1 / 2}$ in theories of dilute ferromagnetism ${ }^{19,20}$ so it seems that a Curie temperature well in excess of $300 \mathrm{~K}$ should be impossible in a uniform sample with $x=5 \%$, for example.

The reports of high Curie temperatures were therefore greeted with scepticism, and the belief that the data somehow reflect the presence of impurity phases, rather than the intrinsic behavior of the dilute magnetic oxide or nitride. For example, the first report of high temperature ferromagnetism in a dilute magnetic oxide was for Co-doped $\mathrm{TiO}_{2}$ (anatase) by Matsumoto et al., ${ }^{1}$ for which $T_{\mathrm{C}}>300 \mathrm{~K}$ was reported for $1-2 \%$ doping. Subsequent examination of samples of $\mathrm{TiO}_{2}$ revealed the presence of clusters of metallic cobalt, ${ }^{21}$ which were at least partially-responsible for the observed ferromagnetism and magnetotransport properties. ${ }^{22}$ But other samples of Co-doped $\mathrm{TiO}_{2}$, however, have been shown to be ferromagnetic and free of cobalt clusters. ${ }^{23}$ In systems such as $\mathrm{ZnO}$ doped with Co for example, which exhibit an extended range of solid solubility in reducing conditions, ${ }^{24}$ no secondary phases have been found, at least in dilute thin films prepared at high temperature and in a low pressure of oxygen. ${ }^{25,26}$ Furthermore, there is spectroscopic evidence in that case that $\mathrm{Co}^{2+}$ does occupy tetrahedral cation sites in the wurtzite structure. ${ }^{26-30}$

The first report of high-temperature ferromagnetism in $\mathrm{SnO}_{2}$ films was by Ogale et al. ${ }^{8}$ who reported a Curie temperature $T_{\mathrm{c}}=650 \mathrm{~K}$ in a cobalt-doped thin film sample with $x=5 \%$, and an astonishingly large moment of $7.5 \mu_{\mathrm{B}}$ per cobalt ion. High temperature ferromagnetism was subsequently reported for $\left(\mathrm{Sn}_{1-x} \mathrm{Fe}_{x}\right) \mathrm{O}_{2}$ with $x=14 \%$ (Ref. 9) and $x=0.5-5 \%,{ }^{44}\left(\mathrm{Sn}_{1-x} \mathrm{Cr}_{x}\right) \mathrm{O}_{2}$ with $x=5 \%,{ }^{10}\left(\mathrm{Sn}_{1-x} \mathrm{~V}_{x}\right) \mathrm{O}_{2}$ with 
$x=7 \%,{ }^{11}$ and $\left(\mathrm{Sn}_{1-x} \mathrm{Ni}_{x}\right) \mathrm{O}_{2}$ with $x=5 \%,{ }^{12}$ but the Mn-doped material was found to be paramagnetic down to $5 \mathrm{~K} .{ }^{31}$ Ferromagnetism in the $V$-doped films depends on the nature of the substrate on which they are deposited. ${ }^{11}$ Hong et al. found moments as high as $3.0 \mu_{\mathrm{B}}$ per vanadium ion for films on $\mathrm{LaAlO}_{3}$.

Up to now, a systematic study of the high temperature ferromagnetism as a function of cation-doping $x$, or the nature of the transition-metal cation $M$ has been carried out for $\mathrm{ZnO} .{ }^{4}$ Most other investigations have been for a single dopant and a few compositions. There is often little agreement between the results obtained in different laboratories. A plot of all measurements of the average cation moment $m$ versus $x$ for the widely studied $\left(\mathrm{Zn}_{1-x} \mathrm{M}_{x}\right) \mathrm{O}$ system for example, shows scattered values, with no discernable trend. ${ }^{20}$ We have therefore undertaken another systematic investigation of the magnetic and transport properties of a dilute magnetic semiconductor system over a wide range of doping. The $\left(\mathrm{Sn}_{1-x} \mathrm{M}_{x}\right) \mathrm{O}_{2}$ system was chosen because the $\mathrm{SnO}_{2}$ films can be doped with all the $3 d$ transition metal ions, and it is possible to produce uniform thin films with $M=\mathrm{Mn}, \mathrm{Fe}$, or Co over a wide range of composition $0.1<x<30 \%$. Our aim was to develop some understanding of the ferromagnetism in these remarkable $n$-type transparent conducting oxides. ${ }^{32}$ The results are first discussed in terms of carrier-mediated exchange in a spin-split impurity band derived from bound magnetic polarons, ${ }^{33}$ or in a spin-split $4 \mathrm{~s} / 5 \mathrm{~s}$ conduction band, and then in terms of a model of ferromagnetic ordering of moments of molecular orbitals with $2 p$ hole character, which may be associated with defects in the interface region.

\section{EXPERIMENTAL METHODS}

The oxide films were prepared by pulsed-laser deposition (PLD). Ceramic targets $\left(\mathrm{Sn}_{1-x} \mathrm{M}_{x}\right) \mathrm{O}_{2}$, with $0.001<x<0.05$, were synthesized from stoichiometric amounts of high purity 99.99\% $\mathrm{SnO}_{2}$ and $\mathrm{MO}(M=\mathrm{Mn}, \mathrm{Fe}, \mathrm{Co})$ powders. In addition a series of ten $\left(\mathrm{Sn}_{0.985} \mathrm{M}_{0.015}\right) \mathrm{O}_{2}$ targets was prepared, where $M=\mathrm{Sc}-\mathrm{Zn}$. The oxide powders were thoroughly ground under isopropanol, then pressed into pellets and sintered at $1150{ }^{\circ} \mathrm{C}$ for $24 \mathrm{~h}$. The structural and magnetic characteristics of the targets have been reported elsewhere. ${ }^{34} \mathrm{Mi}-$ nor amounts of secondary phases were found in the targets$\mathrm{SnCo}_{2} \mathrm{O}_{4}$ and $\alpha-\mathrm{Fe}_{2} \mathrm{O}_{3}$ in the $\mathrm{Co}$ and $\mathrm{Fe}$ doped samples, respectively. The ceramics with $M=\mathrm{Mn}$ or Fe were ferromagnetic, with small room temperature saturation magnetisation values of 0.2 and $1.8 \mathrm{~A} \mathrm{~m}^{2} \mathrm{Kg}^{-1}$ for $\mathrm{Sn}_{0.95} \mathrm{Mn}_{0.05} \mathrm{O}_{2}$ and $\mathrm{Sn}_{0.95} \mathrm{Fe}_{0.05} \mathrm{O}_{2}$, respectively. Corresponding moments are $0.1 \mu_{\mathrm{B}} / \mathrm{Mn}$ and $1.0 \mu_{\mathrm{B}} / \mathrm{Fe}$, respectively. The Co-doped targets show no ferromagnetism down to $5 \mathrm{~K}^{34}$

Following Ogale et al. ${ }^{8}$ the thin films were deposited on $R$-cut (1 $1 \overline{1} 02)$ sapphire substrates using a $\mathrm{KrF}$ excimer laser operating at $248 \mathrm{~nm}$ and $10 \mathrm{~Hz}$. Laser fluence on the target was $1.8 \mathrm{~J} \mathrm{~cm}^{-2}$. The target-substrate distance was $35 \mathrm{~mm}$ and the oxygen pressure was $10^{-4}$ mbar. The substrate temperature was $750{ }^{\circ} \mathrm{C}$. Film thickness was determined after deposition by small angle $\mathrm{x}$-ray scattering and it was also monitored during deposition using optical reflectivity at $635 \mathrm{~nm}$.
Independent thickness measurements were made by atomic force microscopy (AFM) of a trench milled by argon-ion etching, and by direct observation of a cross section in the transmission electron microscope. A typical deposition rate was $10 \mathrm{~nm} / \mathrm{min}$, with the laser operating at $10 \mathrm{~Hz}$.

Crystal structure measurements were performed using a Philips PW3040 four-circle materials research x-ray diffractometer. This allowed the measurement of off-axis as well as on-axis scans in $\mathrm{SnO}_{2}$ films doped with $\mathrm{V}, \mathrm{Cr}$, or $\mathrm{Mn}$. Inplane and out-of-plane orientation, mosaicity and lattice parameters for each film were determined using $\theta / 2$ scans, rocking curves, area maps, and pole figure measurements. The thin-film optics on this diffractometer do not allow highresolution measurements - a minimum line width of approximately $0.4^{\circ}$ is observable for the (400) reflection of a (100) oriented single crystal silicon wafer. The determination of crystallite size through line width is thus impossible. However, line width from film to film can be compared to give relative mosaicities and a measure of the relative quality of the films. Small-angle measurements were performed using a Philips X'Pert PRO x-ray diffractometer with enhanced optics-a minimum line width of approximately $0.06^{\circ}$ is observable for the (400) reflection of a (100) oriented single crystal silicon wafer.

Scanning electron microscopy (SEM), with energy dispersive $\mathrm{x}$-ray analysis (EDAX) was used for elemental analysis and mapping. Rutherford backscattering spectroscopy (RBS) was employed to determine the chemical composition of the $\mathrm{SnO}_{2}$ films doped with $\mathrm{Fe}$. The samples were analyzed by means of a $2.0 \mathrm{MeV}{ }^{4} \mathrm{He}^{+}$incident beam and the backscattered particles were detected by a $\mathrm{Si}(\mathrm{Li})$ surface barrier detector placed at $165^{\circ}$ with respect to the incident beam direction.

Root mean square surface roughness was determined by atomic force microscopy (AFM) and magnetic contrast was recorded using magnetic force microscopy (MFM). Magnetization measurements were made in a SQUID magnetometer at both $300 \mathrm{~K}$ and $5 \mathrm{~K}$. Curie temperatures $\left(T_{\mathrm{c}}\right)$ were measured using a SQUID magnetometer with a high temperature furnace in a field of $150 \mathrm{mT}$. The ${ }^{57} \mathrm{Fe}$ Mössbauer spectra were collected at room temperature and at $16 \mathrm{~K}$ in transmission geometry with a ${ }^{57} \mathrm{Co}(\mathrm{Rh})$ source, as reported previously. ${ }^{9,34}$

Optical spectra were recorded at room temperature in the range 2-6 eV using a Perkin Elmer dual-beam spectrophotometer. Resistivity measurements were carried out by the standard van der Pauw technique in the temperature range 5-300 K using Au/In contacts. Magnetoresistance was measured in a Quantum Design 14 Tesla PPMS system.

\section{RESULTS}

\section{A. Film composition and structure}

A typical film thickness was $90 \mathrm{~nm}$. The different methods of measuring film thickness consistently agreed to within $\pm 5 \%$. Films were smooth and featureless in SEM, with no evidence of the droplets sometimes seen in films produced by PLD. In TEM the $65 \mathrm{~nm}$ Mn-doped film shows peak-topeak surface undulation of $1.5 \mathrm{~nm}$. AFM images of a thick 


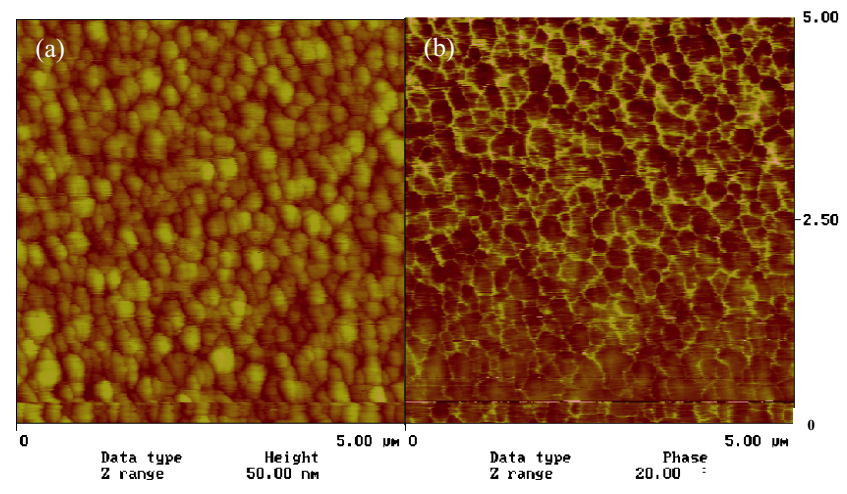

FIG. 1. (Color online) (a) Atomic force microscope image of a film of composition $\left(\mathrm{Sn}_{0.75} \mathrm{Fe}_{0 . .25}\right) \mathrm{O}^{2}$ and (b) magnetic force microscope image of the same area, corrected for surface topology.

(240 nm) $\mathrm{Sn}_{0.75} \mathrm{Fe}_{0.25} \mathrm{O}_{2}$ film show a blister-like surface topology with rms roughness of $5 \mathrm{~nm}$ [Fig. 1(a)].

The compositions of the films are very different from those of the ceramic targets from which they are made. The nominal composition $x^{\prime}$ is plotted against the measured composition $x$, determined by EDAX analysis, in Fig. 2 for the $\left(\mathrm{Sn}_{1-x} \mathrm{M}_{x}\right) \mathrm{O}_{2}$ series, where $M=\mathrm{Mn}, \mathrm{Fe}, \mathrm{Co}$. Pulsed-laser deposition does not maintain the stoichiometry of the target in face of the volatility of $\mathrm{SnO}_{2}$, which is resputtered from the growing film. In fact the films contain roughly four times as much of the $3 d$ element as the targets. A lesser enhancement of $3 d$ dopant concentration has been reported in PLD $\mathrm{ZnO}$ films doped with $\mathrm{Co}$ or other transition metals. ${ }^{16,35}$

The compositional uniformity was investigated in Fedoped $\mathrm{SnO}_{2}$ films using RBS spectroscopy, the spectra being analyzed using the RUMP program. ${ }^{36}$ An RBS spectrum of a $150 \mathrm{~nm}$ Fe-doped $\mathrm{SnO}_{2}$ film produced from an $\mathrm{Sn}_{0.97} \mathrm{Fe}_{0.03} \mathrm{O}_{2}$ target is shown in Fig. 3 where the edges for each element are indicated by arrows. It can be noted that the Sn peak and the dopant peak are well separated. The uniform composition of the film is evidenced by the symmetry of the

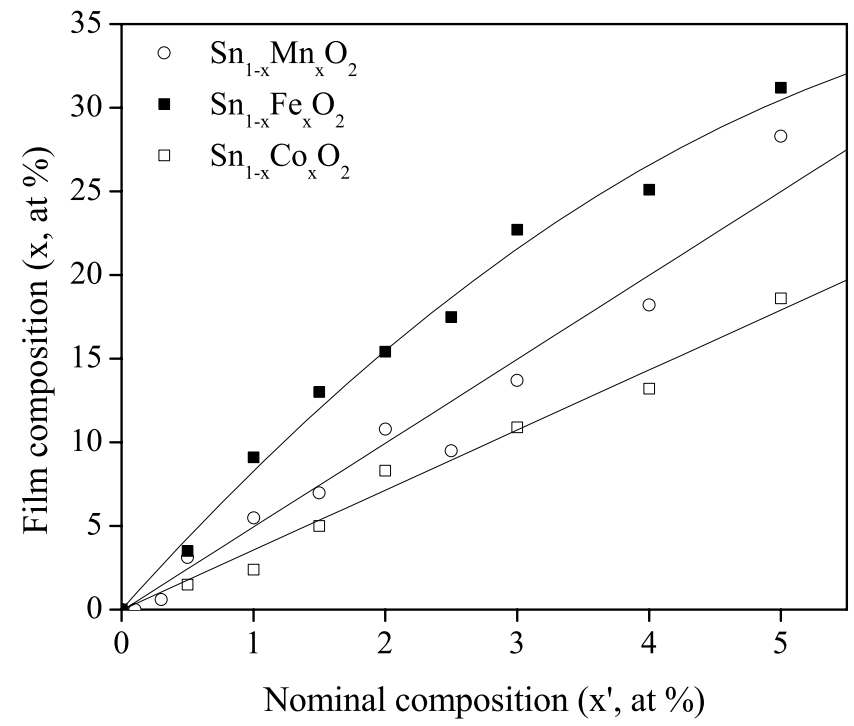

FIG. 2. Plot of the composition of the film $x$ versus the nominal composition of the target determined by EDAX measurements.

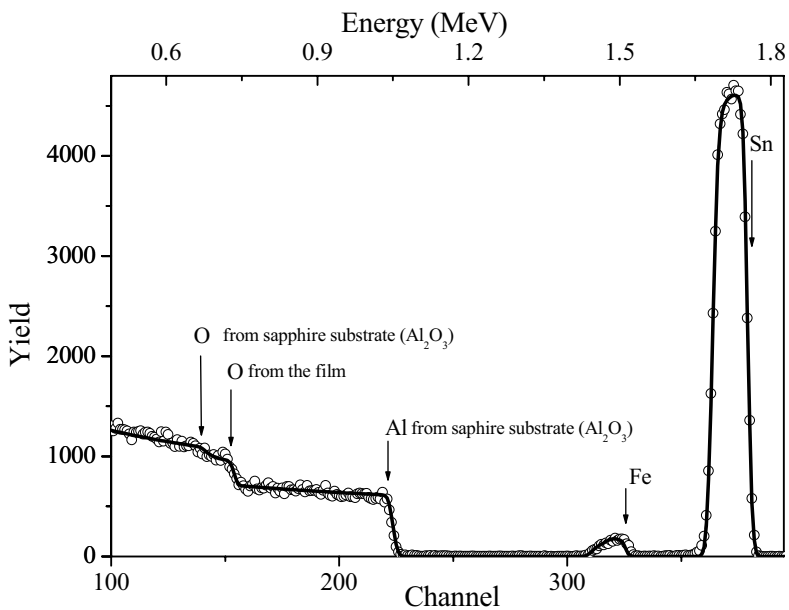

FIG. 3. RBS spectra (dots) of film grown from $\left(\mathrm{Sn}_{0.97} \mathrm{Fe}_{0.03}\right) \mathrm{O}_{2}$. Line shows the simulation using the RUMP program.

Sn peak. The Fe concentration obtained from the fit in Fig. 3 is 12 at. \% at the surface but it drops to a lower value towards the film-substrate interface. A cross section of a $\mathrm{Sn}_{0.94} \mathrm{Mn}_{0.06} \mathrm{O}_{2}$ thin film was examined by scanning transmission electron microscopy. No appreciable compositional variation was found across the $65 \mathrm{~nm}$ film.

An x-ray diffraction pattern is shown in Fig. 4 for a typical, cobalt doped, film on $R$-cut sapphire. The full width at half maximum (FWHM) from rocking curve measurements is $0.6^{\circ}$ for a $150 \mathrm{~nm}$ thick $\mathrm{Sn}_{0.93} \mathrm{Co}_{0.07} \mathrm{O}_{2}$ film, similar to previous reports on CVD films. ${ }^{37}$ For all the other dopants, the width of the rocking curve is between 0.6 and $0.8^{\circ}$, with the exception of $\mathrm{Cr}$, for which the width was $1.3^{\circ}$. There is a strong (101) texture, with no evidence of secondary phases except for an unidentified peak at $2 \theta=145.5^{\circ}$ in a few of the Mn-doped films. From these data, we can only obtain the $d_{101}$ lattice spacing, which is plotted as a function of composition in Fig. 5. The bulk value of $d_{101}$ for $\mathrm{SnO}_{2}$ is $2.64 \AA$, so the films are dilated perpendicular to the plane of the substrate. The strain does not vary with film thickness, as indicated as the insert to Fig. 5.



FIG. 4. X-ray diffraction pattern for a thin film of $\left(\mathrm{Sn}_{0.93} \mathrm{Co}_{0.07}\right) \mathrm{O}_{2}$. One insert shows the rocking curve with a FWHM of $0.6^{\circ}$. The second insert shows the small angle $\mathrm{x}$-ray scattering and simulation for a $50 \mathrm{~nm}$ cobalt-doped film. 


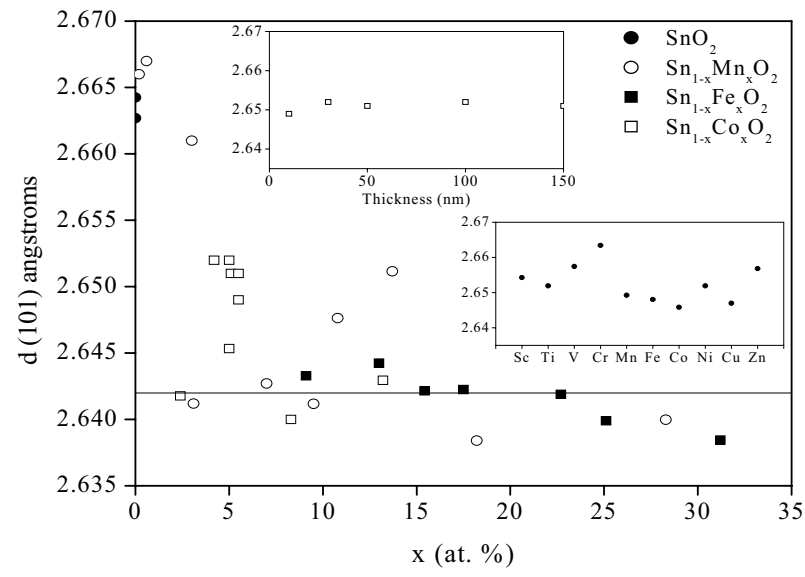

FIG. 5. The $d_{101}$ lattice spacing for $\left(\mathrm{Sn}_{1-x} M_{x}\right) \mathrm{O}_{2}$ films with $M=\mathrm{Mn}, \mathrm{Fe}, \mathrm{Co}$ - the solid line indicates the value for bulk $\mathrm{SnO}_{2}$. The first insert displays the variation of the $d_{101}$ spacing as a function of film thickness in a series of $\mathrm{Sn}_{0.95} \mathrm{Co}_{0.05} \mathrm{O}_{2}$ thin films, while the second shows how $d_{101}$ varies with transition metal dopant at a nominal doping level of $x=0.05$.

A full set of lattice parameters was obtained for $\mathrm{SnO}_{2}$ films doped with $\mathrm{V}, \mathrm{Cr}$, or $\mathrm{Mn}$, using least-squares fits to a triclinic cell of the position of 18 off-axis reflections. The values are the same within $2 \%$, and show that the films are indeed distorted from tetragonal. For the chromiumdoped film (uncertainty shown in brackets) $a=4.720(2)$, $b=4.715(4), \quad c=3.193(2), \quad \alpha=90.03(4)^{\circ}, \quad \beta=89.09(5)^{\circ}$, $\gamma=90.00(4)^{\circ}$.

The pole figure for the $\{101\}$ family of planes of a chromium-doped film is shown in Fig. 6. There are two orientations present, but one orientation is much stronger than the other. Similar results are observed for films doped with V or Mn. The two orientations differ only by an $180^{\circ}$ in-plane rotation, and both could be expected to be present due to the twofold symmetry of the $R$-plane sapphire surface. The conclusion is that the films are highly oriented.

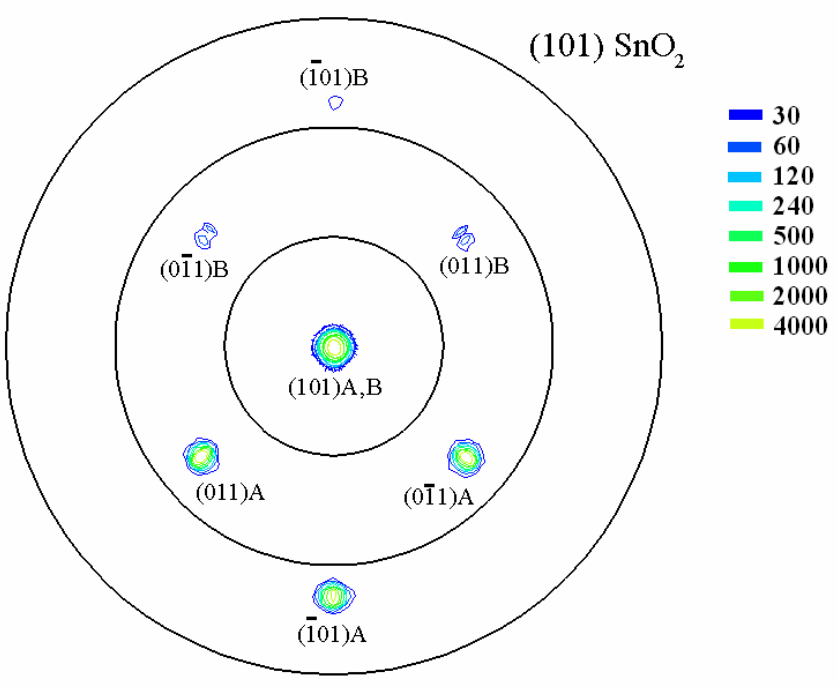

FIG. 6. (Color online) Pole figure of the $\{101\}$ family of planes for a thin film of $\left(\mathrm{Sn}_{0.96} \mathrm{Cr}_{0.04}\right) \mathrm{O}_{2}$.
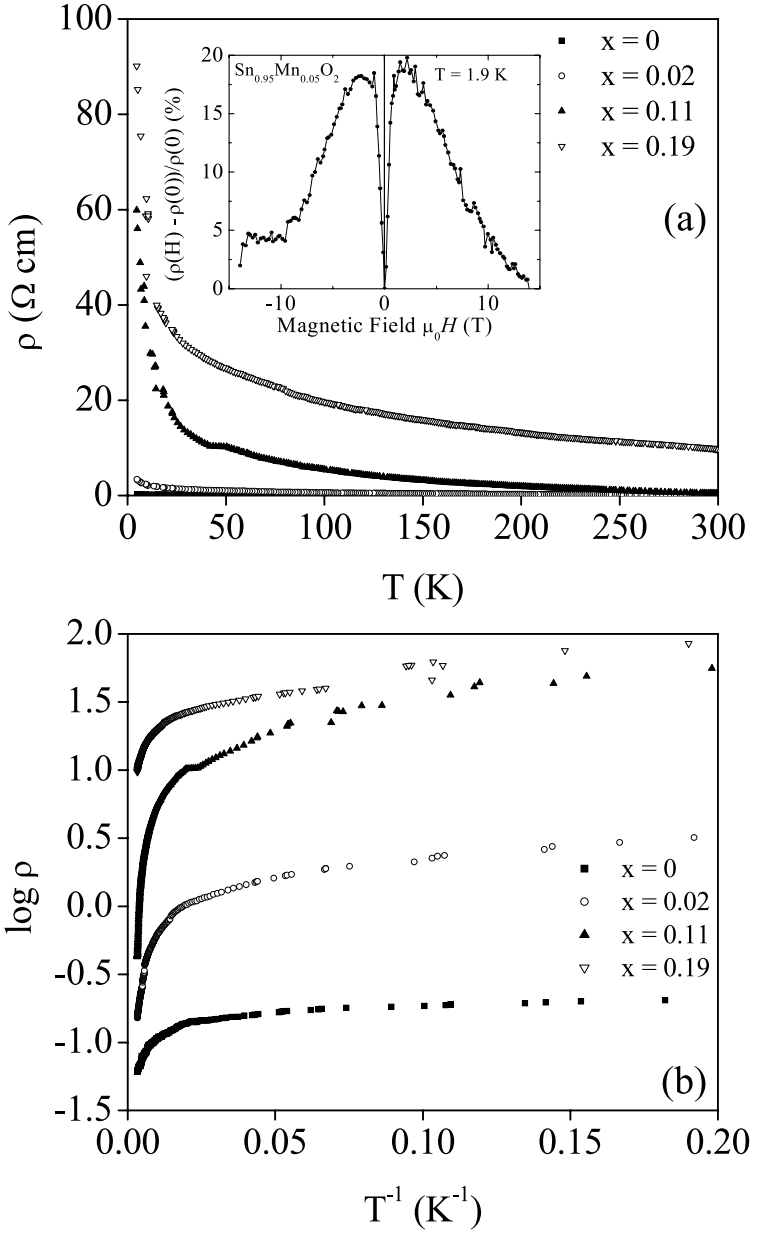

FIG. 7. Resistivity of the $\left(\mathrm{Sn}_{1-x} \mathrm{Co}_{x}\right) \mathrm{O}_{2}$ series plotted (a) on a linear scale and (b) on a logarithmic scale versus $1 / T$.

\section{B. Electrical and electronic properties}

The electrical conductivity of the end member is that of a degenerate $n$-type semiconductor (Fig. 7). Resistivity at room temperature is $7.2 \mathrm{~m} \Omega \mathrm{cm}$, and the activation energy at low temperatures is only $0.2 \mathrm{meV}$. The Hall coefficient $R_{\mathrm{H}}=4.3 \Omega m \mathrm{~T}^{-1}$, yields a carrier concentration $n_{\mathrm{e}}$ of $1.4 \times 10^{25} \mathrm{~m}^{-3}$ in a one-band model, and a mobility of $100 \mathrm{~cm}^{2} \mathrm{~V}^{-1} \mathrm{~s}^{-1}$. For comparison, the apparent carrier concentration in a $4 \%$ Co-doped film is $1.2 \times 10^{24} \mathrm{~m}^{-3}$ at $100 \mathrm{~K}$. Hall voltage was dominated by magnetoresistance contributions below $100 \mathrm{~K}$. No anomalous Hall effect was observed. The cation density in $\mathrm{SnO}_{2}$ is $2.8 \times 10^{28} \mathrm{~m}^{-3}$, so the electronic doping level $\delta$ is $0.05 \%$. On increasing $x$, the oxides become progressively more resistive (Fig. 7). With Co doping films are conducting for all values of $x$, but films with $x>15 \%$ for $\mathrm{Fe}$ or $x>7 \%$ for Mn have a resistance greater than $40 \mathrm{M} \Omega$. The films doped with $\mathrm{Cr}$ or $\mathrm{Ni}$ are insulating.

The magnetoresistance measured at $1.9 \mathrm{~K}$ for $\mathrm{Sn}_{0.95} \mathrm{Mn}_{0.05} \mathrm{O}_{2}$ film is shown as inset in Fig. 7. The magnetoresistance ratio at $1.9 \mathrm{~K}$ is about $18 \%$. The resistance has an initial positive, quadratic variation with field while saturating in about 2 Tesla. In higher fields, there is a slowlysaturating negative term, which may be due to ionized impurity scattering. This behavior can be attributed to the standard 


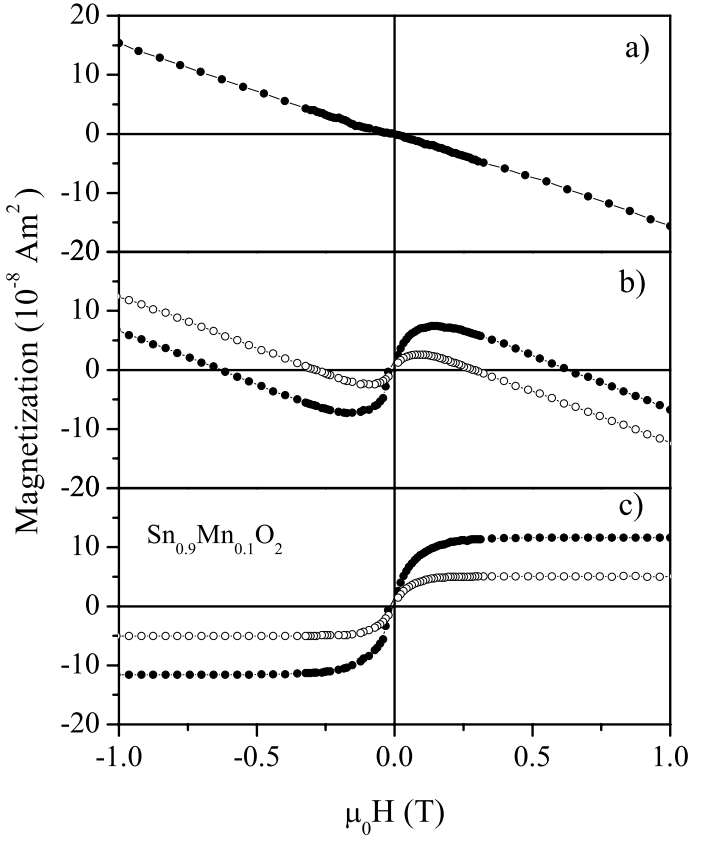

FIG. 8. Magnetization curves of films grown from (a) $\mathrm{SnO}_{2}$ and (b) from $\mathrm{Sn}_{0.98} \mathrm{M}_{0.02} \mathrm{O}_{2}$ targets. Data for the Mn-doped are shown for the field applied parallel $(\bigcirc)$ and perpendicular $(\bullet)$ to the plane of the substrate. The magnetism of the film after correcting for the sapphire substrate signal is indicated in the panel (c)

two-band picture with a possible weak localization contribution below $20 \mathrm{~K}$. No measurable magnetoresistance is observed above $100 \mathrm{~K}$. The cobalt-doped film was too resistive to measure at $1.9 \mathrm{~K}$.

Optical absorption spectra for $\mathrm{SnO}_{2}$ pure and doped films show a broad absorption edge at $330 \mathrm{~nm}(3.8 \mathrm{eV})$, corresponding to the band gap.

\section{Magnetic properties}

Magnetization curves were measured for all samples at $5 \mathrm{~K}$ and at $300 \mathrm{~K}$ in the SQUID magnetometer. Data are corrected for the diamagnetism of the substrate, which gives a slope of $-1.8 \times 10^{-7} \mathrm{~A} \mathrm{~m}^{2} \mathrm{~T}^{-1}$. Some representative results are presented in Fig. 8. Figure 8(a) shows the diamagnetic signal measured for the substrate with an undoped $\mathrm{SnO}_{2}$ film. Figure 8(b) shows magnetization measured on a $\left(\mathrm{Sn}_{0.90} \mathrm{Mn}_{0.10}\right) \mathrm{O}_{2}$ film. There is a remarkable difference when the field is applied parallel or perpendicular to the film plane. This anisotropy varies from sample to sample, but the magnetic moment at saturation can be as much as four times greater when the field is applied perpendicular to the film plane than it is in the parallel direction. The SQUID magnetometer was calibrated separately for the two directions using a film of $\mathrm{Fe}_{3} \mathrm{O}_{4}$. The calibration constant was $19 \%$ smaller for the parallel orientation than for the perpendicular orientation. It must be remembered that the mass of the substrate is typically one thousand times greater than that of the film, so the procedure for data reduction whereby the diamagnetic contribution of the substrate is determined by the slope from 3 to $5 \mathrm{~T}$ does not allow any high field slope of the film magnetization in this region to be determined.

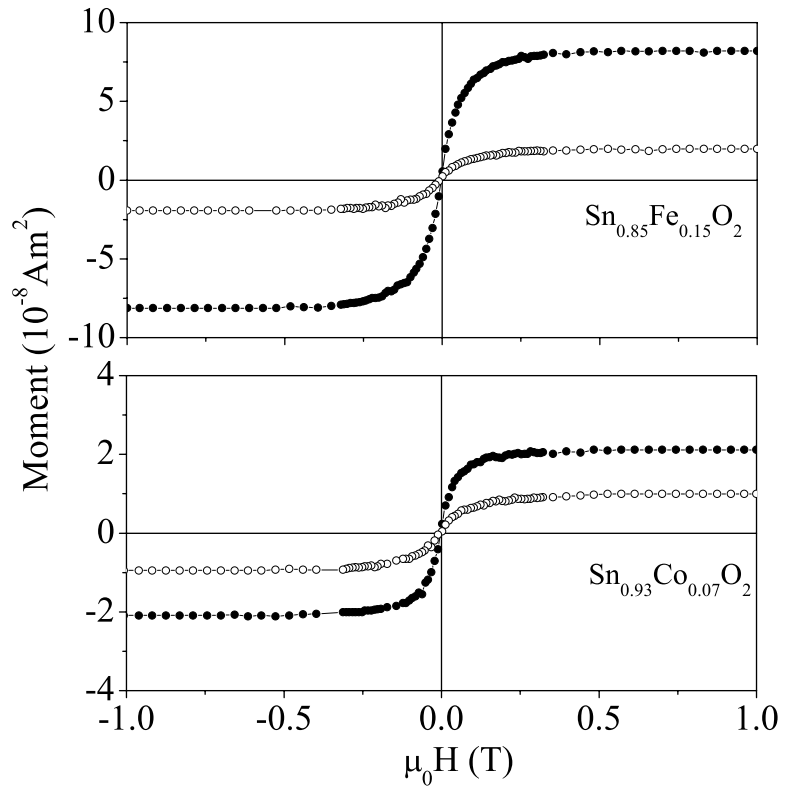

FIG. 9. Magnetization curves for thin films of $\left(\mathrm{Sn}_{1-x} \mathrm{M}_{x}\right) \mathrm{O}_{2}$ with $M=\mathrm{Fe}$ or $\mathrm{Co}$, measured with the field applied parallel $(\bigcirc)$ and perpendicular $(\bullet)$ to the film plane.

Figure 9 presents data on $\mathrm{Co}$ and $\mathrm{Fe}$ doped $\mathrm{SnO}_{2}$ films deposited from $\mathrm{Sn}_{0.98} \mathrm{M}_{0.02} \mathrm{O}_{2}$ targets, which show similar anisotropy to the Mn-doped films. For all films, the magnetisation curves at $5 \mathrm{~K}$ differed by less than $10 \%$ from those measured at room temperature, from which we infer that the Curie temperatures $\left(T_{\mathrm{c}}\right)$ are well above room temperature in all samples. $T_{\mathrm{c}}$ was measured directly from a thermal scan in one case, an Fe-doped sample with $x=14 \%$, and it was found to be $610 \mathrm{~K}^{9}$

Particularly interesting is the plot of magnetization expressed as moment per transition-metal cation in Fig. 10. Despite the scatter, there is a distinct trend. The moment increases steadily as $x$ is reduced, reaching values comparable to, or even exceeding the free-ion spin only values when $x<0.02$. The moment becomes small $\left(<0.2 \mu_{\mathrm{B}}\right)$ beyond the percolation threshold, which is $x_{\mathrm{p}}=0.25$ for the body-centered tetragonal rutile structure. Figure 11 shows magnetization curves for Co-doped films with $x=5 \%$ of different thickness. There is no systematic thickness dependence; the film moment is very roughly $5 \times 10^{15} \mu_{\mathrm{B}}$, regardless of film thickness, which corresponds to $220 \mu_{\mathrm{B}} \mathrm{nm}^{-2}$ of substrate area.

The magnetization measurements for films doped with the series of $3 d$ elements from $\mathrm{Sc}-\mathrm{Zn}$ shows that only films containing $\mathrm{Cr}, \mathrm{Mn}, \mathrm{Fe}, \mathrm{Co}$, or $\mathrm{Ni}$ are magnetic at room temperature, with the largest moments being found for Fe (Fig. 12). All compositions with $\mathrm{Mn}, \mathrm{Fe}$, and Co dopants are ferromagnetic. Little hysteresis is observed except for the Mn compound with $x=28 \%$ and for the Fe compounds with $x>13 \%$. A typical value of coercivity for the lower-doped films is $H_{\mathrm{c}}=4 \mathrm{kA} \mathrm{m}^{-1}$ with a remanence ratio $M_{\mathrm{r}} / M_{\mathrm{s}}=5 \%$.

The magnetic contrast seen in magnetic force microscopy (MFM), Fig. 1(b), appears to decorate the topology, consistent with uniform in-plane magnetization of the films. Both the moment and coercivity of highly Fe-doped samples were 

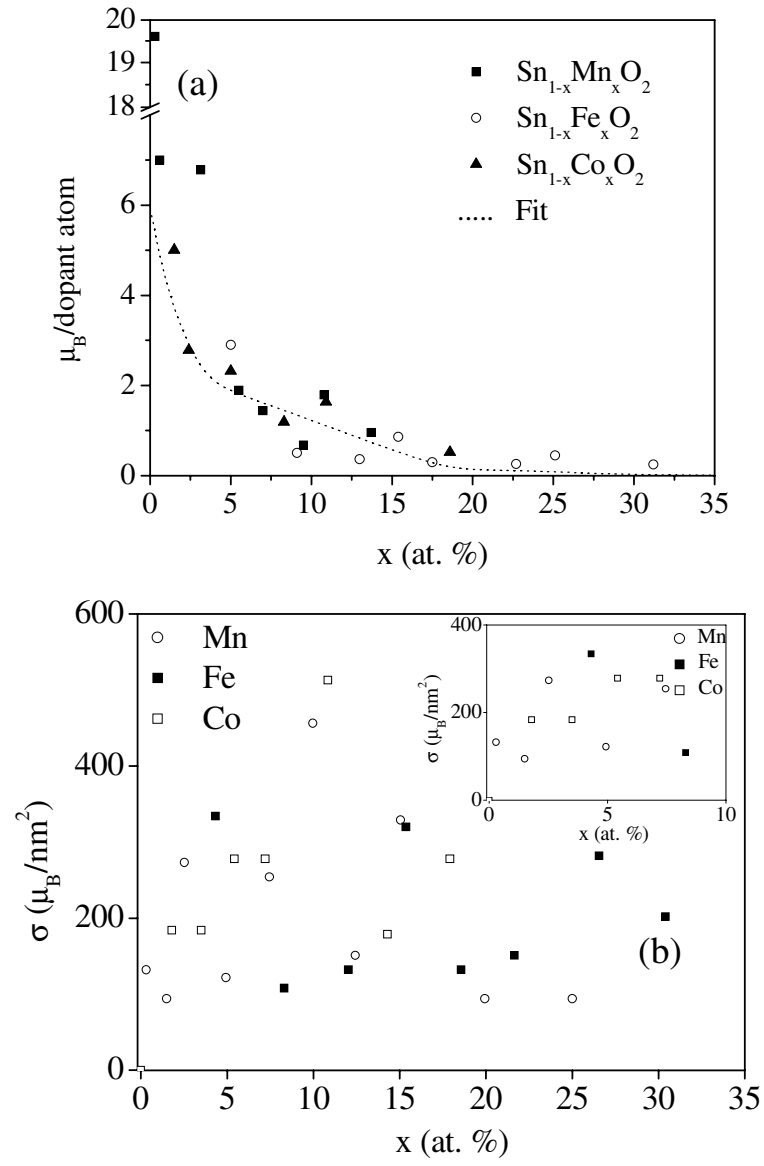

FIG. 10. (a) Magnetic moment of $\left(\mathrm{Sn}_{1-x} \mathrm{M}_{x}\right) \mathrm{O}_{2}$ films, $M=\mathrm{Mn}$, Fe or Co, expressed per dopant atom. (b) Magnetic moments measured on thin films of $\left(\mathrm{Sn}_{1-x} \mathrm{M}_{x}\right) \mathrm{O}_{2}$ with $M=\mathrm{Mn}, \mathrm{Fe}$, or Co expressed in Bohr magnetons per unit substrate area.

stable in time, the same values were found when films were measured just after deposition as over three following years. However, the moment in the weakly-coercive Co- and Mndoped films decays with time and diminished by a factor of ten after two years.

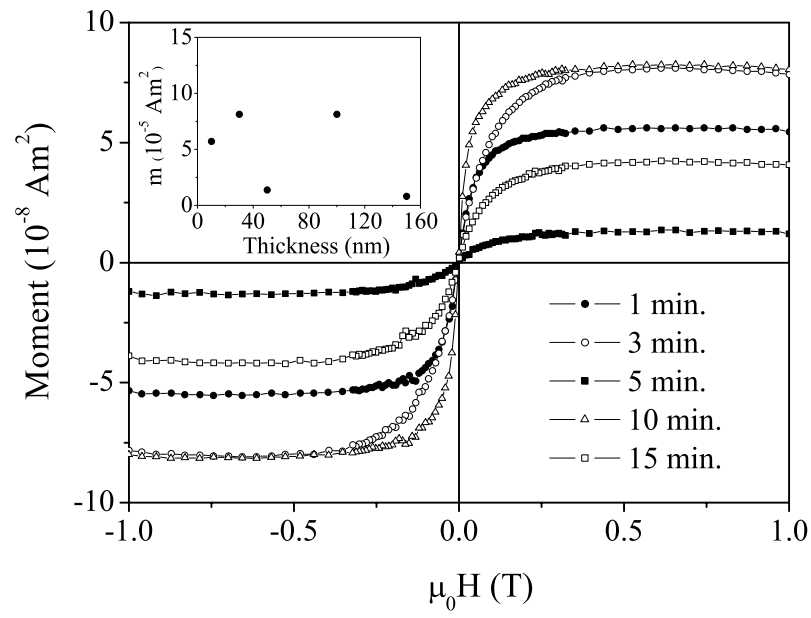

FIG. 11. Thickness dependence of the moment of $\left(\mathrm{Sn}_{0.95} \mathrm{Co}_{0.05}\right) \mathrm{O}_{2}$ films.



FIG. 12. Magnetic moment of $\left(\mathrm{Sn}_{1-x} \mathrm{M}_{x}\right) \mathrm{O}_{2}$ films, $M=\mathrm{Sc}, \mathrm{Ti}, \ldots, \mathrm{Cu}, \mathrm{Zn}$ measured at room temperature with the field applied perpendicular to the film plane. The moment is expressed as $\mu_{\mathrm{B}} / \mathrm{TM}$.

\section{Mössbauer spectra}

Mössbauer spectra were reported previously for a film made with ${ }^{57} \mathrm{Fe}_{2} \mathrm{O}_{3} .{ }^{9}$ The production method differs from that used for the films reported here insofar as $\mathrm{Fe}_{2} \mathrm{O}_{3}$ rather than $\mathrm{FeO}$ is used as a starting material for target preparation. Nonetheless, the spectra gives some useful insight into the magnetism. All the iron is in the ferric form in octahedral sites, with an isomer shift of 0.29 and $0.38 \mathrm{~mm} \mathrm{~s}^{-1}$ with respect to iron metal for paramagnetic and magnetically ordered subspectra respectively, but only $23 \%$ of the iron was magnetically ordered at room temperature in a sample with $x=14 \%$. The moment of the sample was $2.2 \mathrm{~A} \mathrm{~m}^{2} \mathrm{~kg}^{-1}$, which corresponds to a moment of $1.8 \mu_{\mathrm{B}}$ per ordered iron ion. The hyperfine field, $51.2 \mathrm{~T}$ indicates an iron moment of close to $5 \mu_{\mathrm{B}}$. This suggests a degree of antiferromagnetic coupling among the ordered iron moments or between the iron and some magnetic defects. Other doped samples with $x>14 \%$ which exhibited open hysteresis loops having $\mu_{0} H_{\mathrm{C}} \sim 125 \mathrm{mT}$ were found to contain most of the iron in the form $\mathrm{Fe}_{3} \mathrm{O}_{4}$ impurities.

\section{DISCUSSION}

\section{A. Charge state}

The first point in a discussion of the magnetic and electric properties of these dilute ferromagnetic oxides is to try to establish the charge state of the transition-metal dopant cations. For manganese, there are three possibilities, $\mathrm{Mn}^{2+}\left(3 d^{5}\right.$, $91 \mathrm{pm}), \mathrm{Mn}^{3+}\left(3 d^{4}, 70 \mathrm{pm}\right)$, and $\mathrm{Mn}^{4+}\left(3 d^{3}, 52 \mathrm{pm}\right)$. The electron configuration and ionic radius of each ion in $\mathrm{pm}$ is given in brackets. The most likely configuration, based on the lattice spacing data in Fig. 5 is $\mathrm{Mn}^{3+}$ (or possibly a mixture of $\mathrm{Mn}^{2+}$ and $\mathrm{Mn}^{4+}$ ). The ionic radius of $\mathrm{Sn}^{4+}$ in $\mathrm{SnO}_{2}$ is $74 \mathrm{pm}$, and the corresponding oxygen radius in the rutile structure is $135 \mathrm{pm}$. The $\mathrm{Mn}^{4+}$ valence state should lead to a negative strain, which is not observed. 


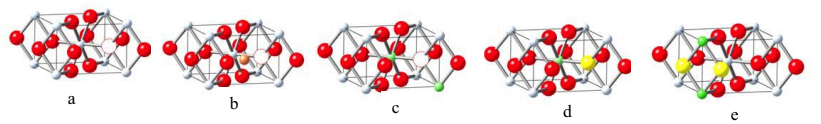

FIG. 13. (Color online) Illustration of defects in $\mathrm{SnO}_{2}$ structure. (a) oxygen vacancy (b) oxygen vacancy and tin interstitial (c) A pair of substitutional $M^{3+}$ cations with a oxygen vacancy (d) An substitutional $M^{3+}$ ion with an oxygen-hole (e) A pair of $M^{3+}$ cations with a peroxide ion.

For iron, little strain is expected because the ionic radius of $\mathrm{Fe}^{3+}$ is similar to that of $\mathrm{Sn}^{4+}$. The data of Fig. 5 are consistent with an $\mathrm{Fe}^{3+}\left(3 d^{5}, 67 \mathrm{pm}\right)$ charge state, which is the one usually found in oxides. The only other possibility, $\mathrm{Fe}^{2+}\left(3 d^{6}, 82 \mathrm{pm}\right)$ would create a lattice dilation similar to $\mathrm{Mn}^{2+}$, which is not observed (Fig. 5). Ferric iron was confirmed by the Mössbauer isomer shift and hyperfine field. ${ }^{9}$

As for $\mathrm{Co}$, the possible charge states are $\mathrm{Co}^{2+}\left(3 d^{7}\right.$, $82 \mathrm{pm})$ and $\mathrm{Co}^{3+}\left(3 d^{6}, 64 \mathrm{pm}\right)$ either of which might be in a low-spin state. The large moments at low concentrations might favor high spin $\mathrm{Co}^{3+}$.

In any case, the transition-metal cations have a lower valence than the tin for which they substitute, so the dopants must somehow influence the defect chemistry. The isolated oxygen vacancy [Fig. 13(a)] captures an electron and forms a $F$-center deep in the gap. The doubly-occupied state $F^{\prime}$ lies above the conduction band edge. The defect believed to lead to conduction in $\mathrm{SnO}_{2}$, is an oxygen vacancy associated with an interstitial tin atom [Fig. 13(b)]. ${ }^{33}$ The $8 i$ octahedral interstitials at $a / 2,0, c / 2$ have the same multiplicity as the adjacent $8 j$ tin sites. More oxygen vacancies would be introduced on doping if two $\mathrm{Sn}^{4+}$ ions are replaced by two $\mathrm{M}^{3+}$ ions together with an $\mathrm{O}^{2-}$ vacancy [Fig. 13(c)] rather than an interstitial $\mathrm{Sn}^{2+}$ ion, but such high levels of nonstoichiometry (up to $10 \%$ ) are likely to destabilize the rutile lattice. Furthermore, $3 d$ doping at levels $x \gg \delta$ has little influence on the conductivity of $\mathrm{SnO}_{2}$-the doping level $x$ has to be very much greater than the donor concentration, $\delta=0.05 \%$, before the films become insulating, at least for $\mathrm{Mn}, \mathrm{Fe}$, and Co doping. The oxygen vacancies associated with the $3 d$ dopants would be expected to trap the electrons which are responsible for the conductivity of $\mathrm{SnO}_{2}^{-}$.

In view of the high doping levels that can be achieved in $\mathrm{SnO}_{2}$, the defects are more likely to be electronic in nature, rather than atomic interstitials or vacancies. A suitable charge-compensating electronic defect is the replacement of a tin ion in its surrounding oxygen octahedron, $\mathrm{Sn}^{4+} \mathrm{O}_{6}^{-2}$, by $\mathrm{M}^{3+} \mathrm{O}^{2-}{ }_{5} \mathrm{O}^{-}$[Fig. 13(d)]. The $\mathrm{O}^{-}$ligand holes are not delocalized at the top of the oxygen $2 p$ band, such as the $4 p$ holes in Mn-doped GaAs for example, because the oxide becomes less conducting, not more conducting on doping. Instead, they will tend to pair up to form $\mathrm{O}_{2}{ }^{2-}$ peroxide ions linking adjacent octahedra, each of which is occupied by an aliovalent cation [Fig. 13(e)]. The $\mathrm{Mn}^{3+}, \mathrm{Fe}^{3+}$, and $\mathrm{Co}^{3+}$ levels in $\mathrm{SnO}_{2}$ must fall in the $2 p-5 s$ gap but the $M^{2+}$ cation levels, with an extra $d$ electron, lie well above the bottom of the conduction band. An effect of doping with $M^{3+}$ impuri- ties is to create random spatial potential fluctuations, which tend to localize the donor electrons, whether they are in the conduction band, or in an impurity band.

\section{B. Magnetic moments}

We now turn to the problem of high-temperature ferromagnetism. First, in $5 \%$ doped $(\mathrm{Sc}, \mathrm{Ti}, \ldots, \mathrm{Cu}, \mathrm{Zn}) \mathrm{SnO}_{2}$ films (Fig. 12), the room temperature magnetism is only found for $\mathrm{Cr}, \mathrm{Mn}, \mathrm{Fe}, \mathrm{Co}$, and $\mathrm{Ni}$. This is unlike in $\mathrm{ZnO}$, prepared in similar conditions, where Ti, V, and even Sc (but not Mn) doping also results in high temperature ferromagnetism in $\mathrm{ZnO} .{ }^{4}$ Ferromagnetism is not linked to electrical conductivity. Only the Co-doped films are conducting for all dopant concentrations, whereas high concentrations of other dopants eventually lead to insulating films.

It is impossible to explain the large moments in Fig. 10 in terms of any known phases that might be present as impurities. Laying aside the lack of evidence for secondary phases, the pure metals Co and Fe have moments of 1.7 and $2.2 \mu_{\mathrm{B}}$ per atom, respectively. Concentrated transition-metal oxides normally exhibit antiferromagnetic superexchange interactions, which lead to antiferromagnetic or ferrimagnetic structures where the average moment per transition-metal cation does not exceed $1.5 \mu_{\mathrm{B}}$. A few examples are $\mathrm{Mn}_{3} \mathrm{O}_{4}, T_{\mathrm{C}}$ $=43 \mathrm{~K}$ which has a moment of $0.6 \mu_{\mathrm{B}} / \mathrm{Mn},{ }^{38} \mathrm{SnMn}_{2} \mathrm{O}_{4}$ which is ferromagnetic, with $T_{\mathrm{C}}=53 \mathrm{~K},{ }^{39} \gamma$ - $\mathrm{Fe}_{2} \mathrm{O}_{3}$ which is ferrimagnetic with $T_{\mathrm{C}}=743 \mathrm{~K}$ and a moment of $1.25 \mu_{\mathrm{B}} / \mathrm{Fe}{ }^{40}$ The data in Fig. 10 leave little doubt that the high-temperature ferromagnetism is an intrinsic property. It is quite implausible that ferromagnetic impurity phases could give rise to the same behavior in the $\mathrm{Mn}, \mathrm{Fe}$, and Co systems. In any case the moments at low concentrations far exceed those of all known ferromagnetic phases.

The variation of magnitude of the magnetic moment in $\mathrm{SnO}_{2}$ shown in Fig. 10 can be partly explained in terms of the distribution of magnetic impurities in the rutile lattice. The idea is that isolated impurities possess the full spin-only moment on, but nearest-neighbor pairs are coupled antiferromagnetically, making no net contribution to the magnetization, triplets contribute $m / 3$, quartets contribute zero and so on. The clusters are assumed to couple ferromagnetically. A calculation was carried out numerically by simulating a body-centered cubic lattice with $2 \times 10^{6}$ lattice sites, occupied at random. The result of the model shown by the dotted line in Fig. 10(a) compares favorably with the data.

The difficulty is the moments in excess of the spin-only values, first observed in $\left(\mathrm{Sn}_{0.95} \mathrm{Co}_{0.05}\right) \mathrm{O}_{2}$ by Ogale et al., ${ }^{8}$ which also appear at low doping levels in the present work. Allowing for likely uncertainty in thickness and composition, we find an average Mn moment for the lowest concentration $x=0.1 \%$ of $20 \pm 1 \mu_{\mathrm{B}}$, which is to be compared with the spin-only value of $4 \mu_{\mathrm{B}}$ for $\mathrm{Mn}^{3+}$. In no case, including that where orbital moments reside on the donor states, could the moment exceed $(5+\delta / x) \mu_{\mathrm{B}}$ per Mn. The spin moment on a ligand hole [Fig. 13(c)] could add at most $1 \mu_{\mathrm{B}}$ per $3 d$ cation. The observed moments at low concentrations are inexplicable if the only source of magnetism in doped $\mathrm{SnO}_{2}$ is the transition metal dopant. 
The fact that all three dopants in Fig. 10 produce hightemperature ferromagnetism with roughly the same upturn in moment at low concentrations, means that the moment of the films is approximately constant, regardless of composition. Similarly, the moment is (very) approximately independent of film thickness (Fig. 11). A possible explanation for such behavior is the presence of magnetic centers in the doped $\mathrm{SnO}_{2}$ films in the vicinity of the substrate/film interface which are not identified with the $3 \mathrm{~d}$ cations. The idea that the interface play a role is supported by the observation that a ferromagnetic moment is observed when V-doped $\mathrm{SnO}_{2}$ films are deposited by PLD on some substrates (eg. $\mathrm{LaAlO}_{3}$ ) but not others $\left(\right.$ eg. $\left.\mathrm{Al}_{2} \mathrm{O}_{3}\right){ }^{11}$ The thickness of the region in which the magnetic centers are located may be inferred from the fact that a $10 \mathrm{~nm}$ film of $\left(\mathrm{Sn}_{0.95} \mathrm{Co}_{0.05}\right) \mathrm{O}_{2}$ exhibits practically the full moment of $220 \mu_{\mathrm{B}} \mathrm{nm}^{-2}$. Furthermore, the moment is so large that it cannot be entirely located at the interface $\left(1 \mathrm{~nm}^{2}\right.$ is the area occupied by about four $\mathrm{SnO}_{2}$ formula units). Undoped $\mathrm{SnO}_{2}$ films show no ferromagnetism. It therefore seems that the defect centers have a nonmagnetic ground state, but that a low-lying magnetic excited state is stabilized by exchange coupling to a $3 d$ dopant ion ${ }^{41}$ (Fig. 13). There is evidence of such a singlet/triplet structure for two-electron defects in other oxides. ${ }^{42,43} \mathrm{In}_{\mathrm{SnO}_{2}}$, peroxide ions are candidates for the two-electron defect centers.

\section{Exchange interactions}

Carrier-mediated ferromagnetic exchange has to be effective whether or not the carriers are delocalized, as indicated by the semiconducting behavior of all the Co-doped samples and the $\mathrm{Mn}$ or $\mathrm{Fe}$ samples with less than $7 \%$ or $15 \%$ of transition metal, and the insulating behavior of the more highly-doped $\mathrm{Mn}$ and Fe materials. The interaction is longrange. It cannot be nearest-neighbor superexchange or double-exchange if the doping is uniform, because the doping level $x$ in all the films is below the percolation threshold. For example, the cation nearest-neighbor distance is $0.37 \mathrm{~nm}$ whereas the average $\mathrm{Mn}-\mathrm{Mn}$ distance in the $x=0.5 \% \mathrm{Mn}$ sample is $1.2 \mathrm{~nm}$.

We explore three approaches to try to understand the exchange coupling and high Curie temperature. In model $A$, electrons in Bohr-like donor orbitals form magnetic polarons spanning several $3 d$ dopant ions, and the magnetic polarons overlap to make a spin-split impurity band. ${ }^{20} \mathrm{~A}$ variant of this is model $B$, where donor states lie close to the bottom of the $5 s$ (Sn) conduction band, and feed a spin-split conduction band. In either case, the $3 d^{\uparrow}$ levels lies in the $2 p-5 s$ gap. As originally proposed, our impurity band model for magnetic semiconductors identified the donor states providing $n$-type conductivity with oxygen vacancies ( $F$ centers) which form an impurity band that mediates the exchange between the dopant cations. The electrons associated with the singlycharged oxygen vacancies occupy $s$-like hydrogenic orbitals which may overlap to form an impurity band. This band is half filled with one electron per vacancy (the two electron per vacancy $F^{\prime}$ states lie much higher in energy and it can be spin polarized by exchange interaction with the $3 d$ ions). In $\mathrm{SnO}_{2}$, the defects giving rise to the conductivity are thought to be the sparse and easily-ionized $\mathrm{Sn}_{i}+\mathrm{V}_{\mathrm{o}}$ centers shown in Fig. 13(a); these defects can also form an impurity band, which mediates exchange.

The effective exchange between the $3 d$ spins and the impurity band electrons in model $A$ is

$$
J_{\mathrm{sd}} \mathbf{S} . \mathbf{s}|\psi(\mathbf{r})|^{2} \Omega,
$$

where $|\psi(\mathbf{r})|^{2}$ is the electron density in the impurity band and $\Omega$ is the volume of the $3 d$ shell, $\mathbf{S}$ the spin of the $3 d$ cations which have volume $\Omega$, and $\mathbf{s}$ is the donor electron spin. The $s d$ exchange constant $J_{\mathrm{sd}}$ couples the $3 d$ states to the electron density $|\psi(\mathbf{r})|^{2}$ in the impurity band. Developing the molecular field expression for the Curie temperature gives the result $^{20}$

$$
T_{\mathrm{C}}=\left[S(S+1) s^{2} x \delta n / 3\right]^{1 / 2} J_{\mathrm{sd}} \omega_{\mathrm{c}} / k_{\mathrm{B}},
$$

where $x$ is the atomic concentration of dopant cations. $\omega_{\mathrm{c}}$ (typical value $6 \%$ ) is the product of cation/anion volume ratio for the oxide and $\delta=n / n_{\mathrm{O}}$ ( $n$ is the density of defects and $n_{\mathrm{O}}$ is the oxygen density $\approx 6 \times 10^{28} \mathrm{~m}^{-3}$ for oxides with a close-packed oxygen lattice). If we take some typical values, $S=3 / 2, s=1 / 2, x=0.1, \delta=0.01, n=1, J_{\mathrm{sd}}=1.5 \mathrm{eV}, \omega_{\mathrm{c}}$ $=0.06$, we arrive at a value $T_{\mathrm{C}}=18 \mathrm{~K}$. There is limited scope for increasing the Curie temperature in this model. The only way to increase $T_{\mathrm{C}}$ significantly is somehow increase the electron density $|\psi(\mathbf{r})|^{2}$ in the vicinity of the magnetic impurities. In order to transfer the necessary electrons from the donor states to each magnetic cation, empty $3 d$ states should also lie close to the Fermi level, where they hybridize with the impurity band providing transfer of $0.01-0.02$ electrons per cation from the impurity band to the $3 d$ ion. Figure 12 suggests this process is most effective for Fe. The electrons in a narrow impurity band may be localized by random potential fluctuations due to the $3 d$ ion impurities or by Coulomb interaction which produce a Mott-Hubbard splitting between the levels derived from singly or doubly-occupied $F$ centers. Localization has no effect on the exchange interactions provided the localization length exceeds the polaron radius. The radius of the donor orbit for $\mathrm{SnO}_{2}$ is $r_{\mathrm{H}}$ $=\left(\varepsilon \mathrm{m} / \mathrm{m}^{*}\right) a_{0} \approx 16 a_{0}$ where $\varepsilon$, the high-frequency dielectric constant is 3.9 , the Bohr radius $a_{0}=0.053 \mathrm{~nm}$ and the effective mass of the carriers $\mathrm{m}^{*} / \mathrm{m}$ is $0.24 .{ }^{20}$

In model $B$, the donors populate the spin-split conduction band. This is equivalent to the RKKY exchange interaction for low electron densities. The expression for $T_{\mathrm{C}}$ in the RKKY model for small values of $2 k_{\mathrm{F}} r$ is ${ }^{20}$

$$
T_{\mathrm{C}} \approx z m^{*} S(S+1) J_{\mathrm{sd}}{ }^{2} \delta\left(n^{5} x / n_{\mathrm{O}}{ }^{2}\right)^{1 / 3}\left(48 \hbar^{2} k_{\mathrm{B}}\right) .
$$

Substituting reasonable values, $J_{\mathrm{sd}}=1.5 \mathrm{eV}, z=12, \mathrm{~S}=5 / 2$, $n=1$, and $x=0.1, \delta=0.01$, we find $J_{\mathrm{RKKY}}=0.23 \mathrm{~K}$, and $T_{\mathrm{C}}$ $=15 \mathrm{~K}$. This again is more than an order of magnitude too low. The way to increase $T_{\mathrm{C}}$ here is to augment the $4 \mathrm{~s}$ character of the conduction band over the $5 s$. The random potential created by the $3 d$ impurities can create a mobility edge at $E_{\mu}$ near the bottom of the the $4 s / 5 s$ conduction band, which leads to a nonconducting ferromagnetic state when $E_{\mathrm{F}}<E_{\mu}$. 

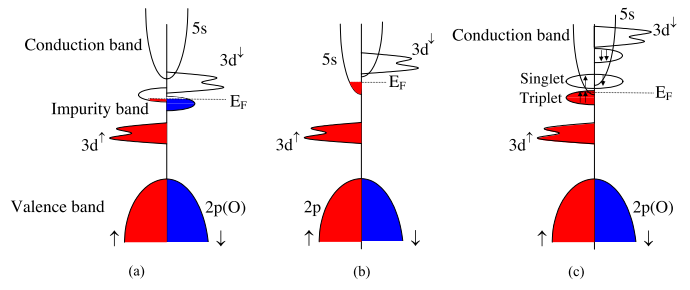

FIG. 14. (Color online) Different models for exchange discussed in the text. (a). Impurity band exchange (b). RKKY exchange (c). Two-electron defect-center exchange.

The predictions of the two models regarding the polarization of the states at the bottom of the conduction band are quite distinct. Model $A$ predicts these states are $\downarrow$, for $\mathrm{Fe}, \mathrm{Co}$, or Ni while model $B$ predicts they are $\uparrow$. A measurement of magnetic dichroism or spin-polarized photoemission may be able to resolve the question of the sign of the spin polarization at the Fermi level, and whether donor electrons mediating the exchange occupy a spin-split impurity band or a spinsplit $4 s / 5 s$ conduction band.

However, there must be a serious doubt whether either of these models tell the full story. The large discrepancy between the predicted and observed values of $T_{\mathrm{C}}$, as well as the observation that only a fraction of the dopant cations is magnetically ordered ${ }^{9,44}$ challenges the idea that the films are magnetically homogeneous. A tendency for the magnetic dopants to line up in threads or sheets could overcome the percolation problem, and the greater exchange energy density in the restricted magnetic regions would lead to higher Curie temperatures. Another problem is that the moment per dopant ion is atmost $(2 S+x / \delta) \mu_{\mathrm{B}}$, which is essentially the spin-only value. Larger moments might be explained if defects, which we supposed to be essentially electronic in nature, are involved more directly in the ferromagnetism.

This leads us to the third approach, model $C$ where the defects have moments. In the simplest case, the moment of a two-hole defect involve a peroxide ion on two adjacent octahedral oxygen cages. More extended oxygen hole orbits can be envisaged, with lower percolation thresholds. The two-hole triplets can themselves form spin-split impurity band [Fig. 14(c)], in the same way as the hydrogenic donor or $F$ center electrons. The extra spin moment introduced in this way can be no more than $1 \mu_{\mathrm{B}}$ per $\mathrm{M}^{3+}$ cation, but there is may be a possibility of an additional orbital moment depending on the symmetry of the defect state. The anisotropy of the susceptibility argues for a large orbital contribution. To account for much larger moments per $3 d$ cation, the number of defects needs to be decoupled from the number of cations. Two-hole defects which are not induced by doping may be present at low $3 d$ cation concentrations. These centers are not magnetic in undoped $\mathrm{SnO}_{2}$, but they could be switched into a magnetic state by exchange coupling to a nearby $3 d$ cation, as illustrated in Fig. 15. The extra moment arising in this way need not be limited to $1 \mu_{\mathrm{B}}$ per $3 d$ cation.

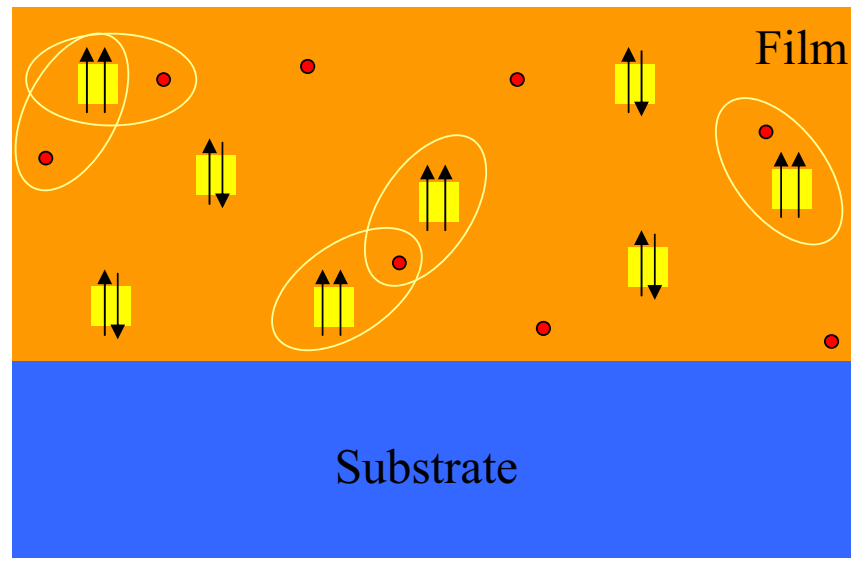

FIG. 15. (Color online) Illustration of the stabilization of twoelectron/hole triplet states by coupling with magnetic dopant cations.

\section{CONCLUSIONS}

The high-temperature ferromagnetism in thin films of $\left(\mathrm{Sn}_{1-x} M_{x}\right) \mathrm{O}_{2}$ with $M=\mathrm{Cr}, \mathrm{Mn}, \mathrm{Fe}, \mathrm{Co}$, or $\mathrm{Ni}$ is an intrinsic effect. The moments at low concentrations approach or surpass the spin-only values, and they cannot be explained in terms of secondary impurity phases. Nor can the anisotropy of the magnetisation of the films be explained in these terms. Absence of anomalous Hall effect indicates that there is negligible $3 d$ density of states at $E_{\mathrm{F}}$.

Exchange, if it is mediated by donor electrons, acts in a way that seems to be equally effective whether the electrons are localized or delocalized. The exchange interactions need to be enhanced by more than an order of magnitude over the values applicable in a simple model of a magnetic polaron impurity band, or an RKKY-type interaction in the conduction band. This requires that the $3 d^{\downarrow}$ states are also present at the Fermi level in the first case, and that the $4 s(M)$ states lie below the $5 s(\mathrm{Sn})$ states in the second case. These models differ in the sign of the spin polarization at the Fermi level.

Much of the magnetic moment, however, is associated with electronic defects or lattice defects, which are already present in the thinnest films. The dopants somehow serve to activate the defect moment, since the undoped films of $\mathrm{SnO}_{2}$ are not ferromagnetic. The high Curie temperature observed for low dopant or defect levels $(\sim 1 \%)$ imply that the defectrelated magnetism is inhomogeneous - it might be associated with grain boundaries for example-or else a new, longrange magnetic coupling mechanism must be found.

\section{ACKNOWLEDGMENTS}

This work forms part of the CINSE project funded by Science Foundation Ireland. L.S. Dorneles is supported by the Irish Research Council for Science, Engineering, and Technology. 
${ }^{1}$ Y. Matsumoto, M. Murakami, T. Shono, T. Hasegawa, T. Fukumura, M. Kawasaki, P. Ahmet, T. Chikyow, S. Koshihara, and H. Koinuma, Science 291, 854 (2001).

${ }^{2}$ Z. Wang, W. Wang and J. Tang, L. D. Tung, L. Spinu, and W. Zhou, Appl. Phys. Lett. 83, 518 (2003).

${ }^{3}$ K. Ueda, H. Tabata, and T. Kawai, Appl. Phys. Lett. 79, 988 (2001).

${ }^{4}$ M. Venkatesan, C. B. Fitzgerald, J. G. Lunney, and J. M. D. Coey, Phys. Rev. Lett. 93, 177206 (2004).

${ }^{5}$ H. Saeki, H. Tabata, and T. Kawai, Solid State Commun. 120, 439 (2001).

${ }^{6}$ P. Sharma, A. Gupta, K. V. Rao, F. J. Owens, R. Sharma, R. Ahuja, J. M. Osorio Guillen, B. Johansson, and G. A. Gehring, Nat. Mater. 2, 673 (2003).

${ }^{7}$ D. B. Buchholz, R. P. H. Chang, J. H. Song, and J. B. Ketterson, Appl. Phys. Lett. 87, 082504 (2005).

${ }^{8}$ S. B. Ogale, R. J. Choudhary, J. P. Buban, S. E. Lofland, S. R. Shinde, S. N. Kale, V. N. Kulkarni, J. Higgins, C. Lanci, J. R. Simpson, N. D. Browning, S. Das Sarma, H. D. Drew, R. L. Greene, and T. Venkatesan, Phys. Rev. Lett. 91, 077205 (2003).

${ }^{9}$ J. M. D. Coey, A. P. Douvalis, C. B. Fitzgerald, and M. Venkatesan, Appl. Phys. Lett. 84, 1332 (2004).

${ }^{10}$ N. H. Hong, J. Sakai, W. Prellier, and A. Hassini, J. Phys.: Condens. Matter 17, 1697 (2005).

${ }^{11}$ N. H. Hong and J. Sakai, Physica B 358, 265 (2005).

${ }^{12}$ N. H. Hong, J. Sakai, N. T. Huong, N. Poirot, and A. Ruyter, Phys. Rev. B 72, 045336 (2005); N. H. Hong, A. Ruyter, W. Prellier, J. Sakai, and N. T. Huong, J. Phys.: Condens. Matter 17, 6533 (2005).

${ }^{13}$ S. Sonoda, S. Shimizu, T. Sasaki, Y. Yamamoto, and H. Hori, J. Cryst. Growth 237, 1358 (2002).

${ }^{14}$ D. Kumar, J. Antifakos, M. G. Blamire, and Z. H. Barber, Appl. Phys. Lett. 84, 5004 (2004).

${ }^{15}$ C. Liu, F. Yun, and H. Morkoç, J. Mater. Sci.: Mater. Electron. 16, 555 (2005).

${ }^{16}$ C. B. Fitzgerald, M. Venkatesan, J. G. Lunney, L. S. Dorneles, and J. M. D. Coey, Appl. Surf. Sci. 247, 493 (2005).

${ }^{17}$ A. M. Nazmul, S. Sugahara, and M. Tanaka, Phys. Rev. B 67, 241308(R) (2003).

${ }^{18}$ T. Dietl, Semicond. Sci. Technol. 17, 377 (2002).

${ }^{19}$ A. Kaminski and S. Das Sarma, Phys. Rev. Lett. 88, 247202 (2002).

${ }^{20}$ J. M. D. Coey, M. Venkatesan, and C. B. Fitzgerald, Nat. Mater. 4, 173 (2005).

${ }^{21}$ J. Y. Kim, J. H. Park, B. G. Park, H. J. Noh, S. J. Oh, J. S. Yang, D. H. Kim, S. D. Bu, T. W. Noh, H. J. Lin, H. H. Hsieh, and C. T. Chen, Phys. Rev. Lett. 90, 017401 (2003).
${ }^{22}$ S. A. Chambers, S. Thevuthasan, R. F. C. Farrow, R. F. Marks, J. U. Thiele, L. Folks, M. G. Samant, A. J. Kellock, N. Ruzycki, D. L. Ederer, and U. Diebold, Appl. Phys. Lett. 79, 3467 (2001).

${ }^{23}$ S. R. Shinde, S. B. Ogale, J. S. Higgins, H. Zheng, A. J. Millis, V. N. Kulkarni, R. Ramesh, R. L. Greene, and T. Venkatesan, Phys. Rev. Lett. 92, 166601 (2004).

${ }^{24}$ D. P. Norton, S. J. Pearton, A. F. Hebard, N. Theodoropoulou et al., Appl. Phys. Lett. 82, 239 (2003).

${ }^{25}$ K. Rode, A. Anane, R. Mattana, J. P. Contuor et al., J. Appl. Phys. 93, 7676 (2003).

${ }^{26}$ S. Ramachandran, A. Tiwari, and J. Narayan, Appl. Phys. Lett. 84, 5255 (2004).

${ }^{27}$ K. J. Kim and Y. R. Park, Appl. Phys. Lett. 81, 1420 (2001).

${ }^{28}$ D. A. Schwartz, N. S. Norberg, Q. P. Nguyen, J. M. Parker, and D. M. Gamelin, J. Am. Chem. Soc. 125, 13205 (2003).

${ }^{29}$ A. C. Tuan, J. D. Bryan, A. B. Pakhomov, V. Shutthanandan, S. Thevuthasan, D. E. McCready, D. Gaspar, M. H. Engelhard, J. W. Rogers, K. Krishnan, D. R. Gamelin, and S. A. Chambers, Phys. Rev. B 70, 054424 (2004).

${ }^{30}$ J. Okabayashi, K. Ono, M. Mizuguchi, M. Oshima, Subhra Sen Gupta, D. D. Sarma, T. Mizokawa, A. Fujimori, M. Yuri, C. T. Chen, T. Fukumura, M. Kawasaki, and H. Koinuma, J. Appl. Phys. 95, 3573 (2004).

${ }^{31}$ H. Kimura et al., Appl. Phys. Lett. 80, 94 (2002).

${ }^{32}$ C. Kilic and A. Zunger, Phys. Rev. Lett. 88, 095501 (2002).

${ }^{33}$ T. Kasuya, Solid State Commun. 8, 1635 (1970).

${ }^{34}$ C. B. Fitzgerald, M. Venkatesan, A. P. Douvalis, S. Huber, J. M. D. Coey, and T. Bakas, J. Appl. Phys. 95, 7390 (2004).

${ }^{35}$ L. S. Dorneles, D. O’Mahony, C. B. Fitzgerald, F. McGee, M. Venkatesan, I. Stanca, J. G. Lunney, and J. M. D. Coey, Appl. Surf. Sci. 248, 406 (2005).

${ }^{36}$ L. R. Doolittle, Nucl. Instrum. Methods Phys. Res. B 9, 344 (1985).

${ }^{37}$ A. Tarre, A. Rosental, J. Sundqvist, A. Hårsta, T. Uustare, and V. Sammelselg, Surf. Sci. 532, 514 (2003).

${ }^{38}$ K. Dwight and N. Menyuk, Phys. Rev. 119, 1470 (1960).

${ }^{39}$ D. G. Wickham, N. Menuyk, and K. Dwight, J. Phys. Chem. Solids 20, 316 (1961).

${ }^{40}$ H. Takei and S. Chiba, J. Phys. Soc. Jpn. 21, 1255 (1966).

${ }^{41}$ J. M. D. Coey, J. Appl. Phys. 97, 10D313 (2005).

${ }^{42}$ A. M. Stoneham, Theory of Defects in Solids, Chap. 16 (Clarendon Press, Oxford, 1975).

${ }^{43}$ A. M. Stoneham, A. P. Pathak, and R. H. Bartram, J. Phys. C 9, 73 (1976).

${ }^{44}$ A. Punnoose, J. Hays, A. Thurber, M. H. Engelhard, R. K. Kukkadapu, C. Wang, V. Shutthanandan, and S. Thevuthasan, Phys. Rev. B 72, 054402 (2005). 